\title{
AHP-TOPSIS Method for Learning Object Metadata Evaluation
}

\author{
M. İnce, T. Yiğit, and A. H. Işık
}

\begin{abstract}
Increasing usage of computers in educational systems such as web based learning systems cause huge e-content needs. In this context, Learning Objects (LOs), stored in Learning Object Repositories (LORs), are used to produce e-content and other educational materials. Evaluation and selection of LOs are difficult and time consuming process when LO and their descriptive metadata numbers are high. Therefore, LO selection process is considered as a multi criteria decision making (MCDM) problem. In this study, analytic hierarchy process - technique for order of preference by similarity to ideal solution (AHP-TOPSIS) methods are combined for selection of LOs from web-based Intelligent Learning Object Framework LOR that is called ZONESA. The results of the system, used in a real case study, showed that the proposed system can be used effectively to produce appropriate content using LO metadata.
\end{abstract}

Index Terms-Analytic hierarchy process, learning object selection, metadata, topsis.

\section{INTRODUCTION}

In real life world, web based learning and other technology are used for educational purposes excessively [1]. E-contents are used in these systems. Main resources of e-contents are LOs which are reusable elements having identifier metadata [2]. Metadata has many tag elements to identify LOs in LORs [3]. If there are a lot of LO in the LOR, evaluation and the selection of LOs are difficult process [4]. Moreover, this process may consume huge amount of time and cause unwanted selections [5]. Regarding these problems, LO evaluation process is considered as an optimization and decision making problem. For these reasons, TOPSIS method is combined with AHP to evaluate and select LOs by the help of IEEE LOM metadata.

\section{Material AND MethodS}

LOs can be described shortly as any entity, digital or non-digital reusable object to support educational systems [6]. LORs store LOs to provide e-content for such systems. Having a lot of LOs and metadata, selection and evaluation of LOs in LORs is difficult issue considering complexity of metadata and time waste issues [4]. Some methods are

Manuscript received December 22, 2016; revised February 18, 2017. This work was supported in part by the Scientific and Technological Research Council of Turkey (TUBITAK) under Grant EEEAG 115E600.

M. Ince is with the Vocational School of Technical Sciences, University of Suleyman Demirel, Isparta, 32200, Turkey (e-mail: muratince@sdu.edu.tr).

T. Yiğit is with the Computer Engineering Department, University of Suleyman Demirel, Isparta, 32200, Turkey (e-mail: tuncayyigit@ sdu.edu.tr).

A. H. Işı is with the Computer Engineering Department, University of Mehmet Akif Ersoy, Burdur, 15030, Turkey (e-mail: ahakan@mehmetakif.edu.tr). developed for evaluation and selection of LO with search parameters and criteria. Most ranked LOs are selected as best LOs in [2]. Another method is classification of LOs by using K-means and Kohonen's Self Organizing Maps [7]. Moreover, frequent pattern tree [8], term frequency [9] are used for evaluation and selection of LOs. Yigit et al. [4] and Ince et al. [5] used AHP method for LO selection based on IEEE LOM metadata. The Analytical Hierarch Process (AHP) is the most popular MCDM model to solve complex problems [10]. Having simple theory, basic calculation process, allowing sensitivity analysis, flexibility, both qualitative and quantitative methods are some beneficial aspects of AHP [11]. Although best known and objective MCDM method, AHP is generally criticized for judgment inconsistency, accuracy and weak prioritization methods [11]. TOPSIS method is used for finding ideal solutions in these problems [12]. In order to solve the drawbacks and critics of the AHP, TOPSIS method is combined with AHP to produce the best solutions to difficult and complex MCDM problems such as performance analyzing [13], spaceflight planning [14], cotton quality determination [15] and agent-based recreational fishing [16]. In these studies, the optimized solutions are provided by combined AHP-TOPSIS methods effectively. In this study, AHP-TOPSIS combined method is also used for $\mathrm{LO}$ selection for the first time in such problem.

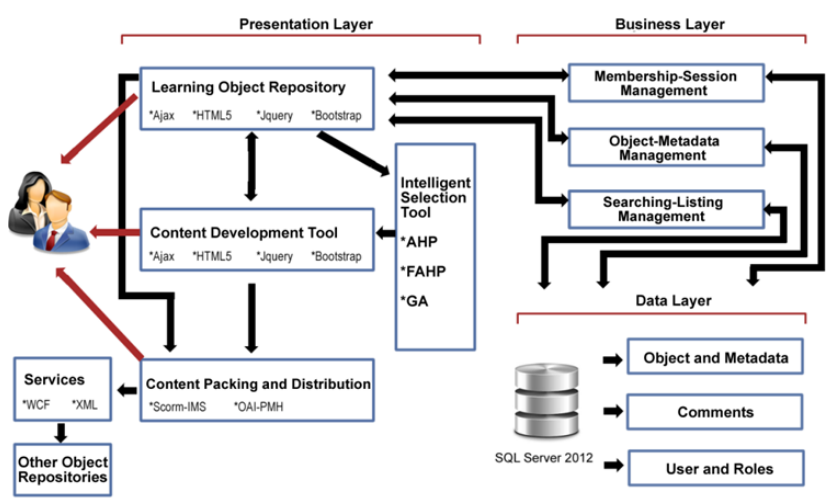

Fig. 1. Architecture of the ZONESA system.

The proposed method is used in the Zonesa project at Suleyman Demirel University/Turkey. The Zonesa system is a web based LOR to store LOs and produce new LOs for educational purposes. The Zonesa system is based on n-tier software architecture to provide fast, durable and expandable system as shown in Fig. 1. Users in the Zonesa can produce, store and share LOs and also prepare new LOs from existing ones. Having responsive web pages, user interfaces of the system can be used for both mobile devices and personal computers. Moreover, the Zonesa has also web services to share LOs with other LORs to provide interoperability and reusability between systems. 


\section{THEORY AND CALCULATIONS}

LOs and metadata are stored in LORs. When the number of metadata is increased, search and selection of LOs become difficult because metadata has a lot of tag elements. In order to get desired LO from LOR, search parameters are queried. If parameters are not matched, nearest LOs can be selected as a result. Huge amount of LOs and metadata causes selection process to be difficult and complex issue. For these reasons, evaluation and selection process can be regarded as multi criteria decision making problem. We used AHP [4] and Fuzzy AHP [5] methods for LO selection in previous studies. In order to solve the drawbacks and critics of the AHP, AHP is combined with the TOPSIS for LO selection and evaluation. Steps of this model as following:

Step 1: The qualitative and quantitative criteria and sub-criteria are defined.

Step 2: Pairwise comparisons of criteria and sub-criteria were performed. In this comparison process, the Saaty's [17] comparison scale was used, which is shown in Table I. Equations from 1 to 9 are derived from Saaty's AHP calculation [18].

$$
C_{i j}=\left[\begin{array}{cccccc}
C_{11} & C_{12} & \cdots & \cdots & \cdots & C_{1 n} \\
C_{21} & C_{22} & \cdots & \cdots & \cdots & C_{2 n} \\
\vdots & \vdots & \vdots & \vdots & \vdots & \vdots \\
\vdots & \vdots & \vdots & \vdots & \vdots & \vdots \\
\vdots & \vdots & \vdots & \vdots & \vdots & \vdots \\
C_{n 1} & C_{n 2} & \cdots & \cdots & \cdots & C_{n n}
\end{array}\right]
$$

where $n$ is criteria count. $C_{j i}=1 / C_{i j}, i$ and $j$ is 1 to $n$.

\begin{tabular}{cl}
\multicolumn{2}{c}{ TABLE I: COMPARISON VALUE SCALE [17] } \\
\hline \hline Scale & Degree of preference \\
\hline 1 & Equal importance \\
2 & Weak \\
3 & Moderate importance \\
4 & Moderate plus \\
5 & Strong importance \\
6 & Strong plus \\
7 & Very strong \\
8 & Very, very strong \\
9 & Extreme importance \\
\hline \hline
\end{tabular}

Step 3: Divide each element in the matrix by its column total to generate normalized pair-wise matrix $\mathrm{X}$.

$$
X_{i j}=\frac{C_{i j}}{\sum_{i=1}^{n} C_{i j}}
$$

where $i$ and $j$ is 1 to $n$.

$$
X_{i j}=\left[\begin{array}{cccccc}
X_{11} & X_{12} & \cdots & \cdots & \cdots & X_{1 n} \\
X_{21} & X_{22} & \cdots & \cdots & \cdots & X_{2 n} \\
\vdots & \vdots & \vdots & \vdots & \vdots & \vdots \\
\vdots & \vdots & \vdots & \vdots & \vdots & \vdots \\
\vdots & \vdots & \vdots & \vdots & \vdots & \vdots \\
X_{n 1} & X_{n 2} & \cdots & \cdots & \cdots & X_{n n}
\end{array}\right]
$$

Using $\mathrm{X}$ matrix, calculate the priority vector weights matrix $\mathrm{W}$.

where $i$ and $j$ is 1 to $n$.

$$
W_{i}=\frac{\sum_{j=1}^{n} X_{i j}}{n}
$$

$$
W=\left[\begin{array}{c}
W_{1} \\
W_{2} \\
\vdots \\
\vdots \\
W_{n}
\end{array}\right]
$$

where $i$ and $j$ is 1 to $n$.

Step 4: Multiply each column pairwise comparison matrix by the corresponding weight.

$$
D=C x W
$$

$$
D_{i j}=\left[\begin{array}{cccccc}
C_{11} & C_{12} & \cdots & \cdots & \cdots & C_{1 n} \\
C_{21} & C_{22} & \cdots & \cdots & \cdots & C_{2 n} \\
\vdots & \vdots & \vdots & \vdots & \vdots & \vdots \\
\vdots & \vdots & \vdots & \vdots & \vdots & \vdots \\
\vdots & \vdots & \vdots & \vdots & \vdots & \vdots \\
C_{n 1} & C_{n 2} & \cdots & \cdots & \cdots & C_{n n}
\end{array}\right] x\left[\begin{array}{c}
W_{1} \\
W_{2} \\
\vdots \\
\vdots \\
\vdots \\
W_{n}
\end{array}\right]=\left[\begin{array}{c}
D_{1} \\
D_{2} \\
\vdots \\
\vdots \\
\vdots \\
D_{n}
\end{array}\right]
$$

where $i$ and $j$ is 1 to $n$.

Step 5: Divide sum of row entries by the corresponding weight. Compute average value as $\lambda$.

$$
E_{i}=\frac{D_{i}}{W_{i}}
$$

where $i$ is 1 to $n$.

$$
\lambda=\frac{\sum_{i=1}^{n} E_{i}}{n}
$$

where $i$ is 1 to $n$.

Step 6: Consistency Index $(C I)$ is calculated as

$$
C I=(\lambda-n) /(n-1)
$$

Step 7: Consistency Ratio $(C R)$ [10] is calculated as $C R=C I / R I$ where $R I$ is Random Index that can be found in Table II.

TABLE II: RANDOM INDEX VALUE SCALE [10]

\begin{tabular}{lllllllllll}
\hline \hline $\mathrm{n}$ & 1 & 2 & 3 & 4 & 5 & 6 & 7 & 8 & 9 & 10 \\
\hline $\mathrm{RI}$ & 0 & 0 & 0.58 & 0.9 & 1.12 & 1.24 & 1.32 & 1.41 & 1.46 & 1.49 \\
\hline \hline
\end{tabular}

Step 8: If $C R$ is lower than 0.1 or equal to 0.1 , the calculations of the criteria are consistent. Thus, weights can be used for TOPSIS calculations.

Step 9:

$$
A_{i j}=\left[\begin{array}{cccccc}
A_{11} & A_{12} & \cdots & \cdots & \cdots & A_{1 n} \\
A_{21} & A_{22} & \cdots & \cdots & \cdots & A_{2 n} \\
\vdots & \vdots & \vdots & \vdots & \vdots & \vdots \\
\vdots & \vdots & \vdots & \vdots & \vdots & \vdots \\
\vdots & \vdots & \vdots & \vdots & \vdots & \vdots \\
A_{m 1} & A_{m 2} & \cdots & \cdots & \cdots & A_{m n}
\end{array}\right]
$$

where $m$ is LO count, $n$ is criteria count. $i$ is 1 to $m, j$ is 1 to $n$.

Step 10: TOPSIS calculations are performed [13] as:

Normalize the matrix $\mathrm{A}_{\mathrm{ij}}$ to get $\mathrm{N}_{\mathrm{ij}}$ matrix by the formula given as

$$
N_{i j}=\frac{A_{i j}}{\sum_{i=1}^{m} A_{i j}^{2}} \text { where } m \text { is LO count. }
$$


Step 11: Determine the weighted decision matrix by multiplying each item with corresponding weight.

$$
K_{i j}=\left[\begin{array}{cccccc}
N_{11} & N_{12} & \cdots & \cdots & \cdots & N_{1 n} \\
N_{21} & N_{22} & \cdots & \cdots & \cdots & N_{2 n} \\
\vdots & \vdots & \vdots & \vdots & \vdots & \vdots \\
\vdots & \vdots & \vdots & \vdots & \vdots & \vdots \\
\vdots & \vdots & \vdots & \vdots & \vdots & \vdots \\
N_{m 1} & N_{m 2} & \cdots & \cdots & \cdots & N_{m n}
\end{array}\right] x\left[\begin{array}{c}
W_{1} \\
W_{2} \\
\vdots \\
\vdots \\
\vdots \\
W_{n}
\end{array}\right]
$$

where $m$ is LO count, $n$ is criteria count. $i$ is 1 to $m, j$ is 1 to $n$.

Step 12: Positive ideal solutions are found as:

$$
A_{j}^{+}=\max \left(K_{i j}\right)
$$

where $i$ is 1 to $m$ that is LO count and $j$ is 1 to $n$ that is criteria count.

Step 13: Negative ideal solutions are found as:

$$
A_{j}^{-}=\max \left(K_{i j}\right)
$$

where $i$ is 1 to $m$ that is LO count and $j$ is 1 to $n$ that is criteria count.

Step 14: Distance and separations are calculated as:

$$
\begin{gathered}
S_{i}^{+}=\sqrt{\sum_{j=1}^{n}\left(K_{i j}-A_{j}^{+}\right)^{2}} \\
S_{i}^{-}=\sqrt{\sum_{j=1}^{n}\left(K_{i j}-A_{j}^{-}\right)^{2}}
\end{gathered}
$$

where $i$ is 1 to $m$ that is LO count and $j$ is 1 to $n$ that is criteria count.

Step 15: Calculate closeness coefficient to ideal solution as:

$$
C_{i}=\frac{s_{i}^{-}}{S_{i}^{-}+S_{i}^{+}}
$$

where $i$ is 1 to $m$ that is $\mathrm{LO}$ count. When $\mathrm{C}_{\mathrm{i}}$ values are ordered by ascending, last ordered alternative LO is selected ideal solution, shown in Fig. 2.

\section{RESULTS AND DISCUSSION}

In presented study, the main criteria and sub-criteria were pairwise compared. The main criteria comparisons are changeable and each user saves their comparisons according to their preferences and priorities. In this study, six criteria is used as following; Learning Resource Type (C1) is educational kind of LO such as figure, exercise, table, simulation. Format (C2) is technical type of LO such as text/html, pdf, gif. Difficulty (C3) is difficulty of the LO according to the target users. Interactivity Level (C4) is the interaction level of user with the LO. Semantic Density (C5) is the degree of the content sense. Pair-wise comparisons of these criteria are shown in Table III and calculated criteria weights are shown in Table IV. Consistency ratio is found as 0.087 that shows criteria are consistent.

Zanakis et al. [19] stated that AHP is uniformly worse than TOPSIS. Similarly, AHP, TOPSIS and AHP-TOPSIS methods are applied to same LOs with same criteria. Ranking distribution of calculated LO points are shown in Table V. AHP-TOPSIS point interval is higher than others. Moreover, Fig. 3 shows the comparisons of these three methods. As shown, distribution of calculated LO points with AHP are not distinguishable. TOPSIS is better than AHP because distributions of calculated LO points with TOPSIS are uniformly distinguishable rather than AHP. Otherwise, slope of the AHP-TOPSIS graphic line is more distinguishing for highest pointed LOs. Therefore, AHP-TOPSIS combined method has best performance for LO evaluation.

TABLE III: COMPARISON MATRIX OF MAIN CRITERIA

\begin{tabular}{llllll}
\hline & $\mathrm{C} 1$ & $\mathrm{C} 2$ & $\mathrm{C} 3$ & $\mathrm{C} 4$ & $\mathrm{C} 5$ \\
\hline $\mathrm{C} 1$ & 1 & 3 & 5 & 6 & 7 \\
$\mathrm{C} 2$ & 0,33 & 1 & 3 & 5 & 6 \\
$\mathrm{C} 3$ & 0,20 & 0,33 & 1 & 4 & 5 \\
$\mathrm{C} 4$ & 0,16 & 0,20 & 0,25 & 1 & 3 \\
$\mathrm{C} 5$ & 0,14 & 0,16 & 0,20 & 0,33 & 1 \\
\hline \hline
\end{tabular}

TABLE IV: CALCULATED WEIGHTS OF CRITERIA

\begin{tabular}{ll}
\hline Criterion & Weight \\
\hline $\mathrm{C} 1$ & 0.4791 \\
$\mathrm{C} 2$ & 0.2579 \\
$\mathrm{C} 3$ & 0.1514 \\
$\mathrm{C} 4$ & 0.0714 \\
$\mathrm{C} 5$ & 0.0400 \\
\hline \hline
\end{tabular}

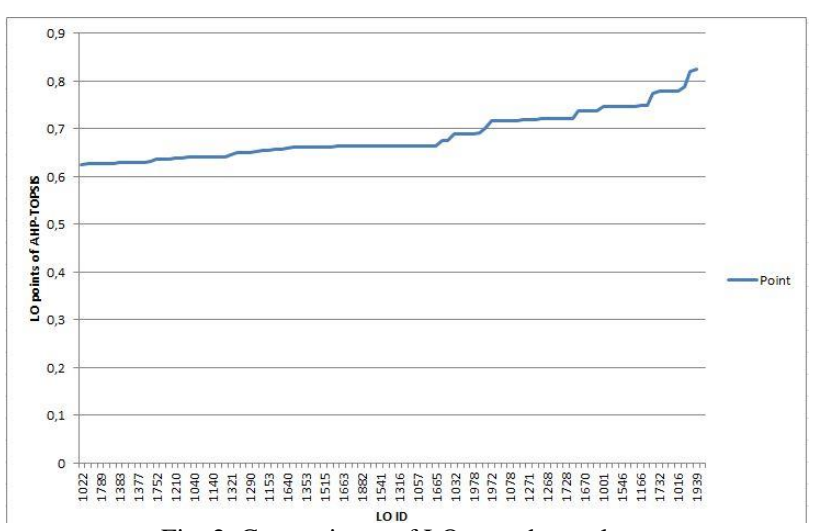

Fig. 2. Comparisons of LO metadata values.

TABLE V: CALCULATED POINT INTERVAL OF METHODS

\begin{tabular}{llll}
\hline \hline Methods & \multicolumn{3}{c}{ Minimum point } \\
\hline AHP & 0,343422267 & 0,466204495 & 0,404813 \\
TOPSIS & 0,093994793 & 0,128775182 & 0,111385 \\
AHP-TOPSIS & 0,62534614 & 0,824534458 & 0,72494 \\
\hline \hline
\end{tabular}

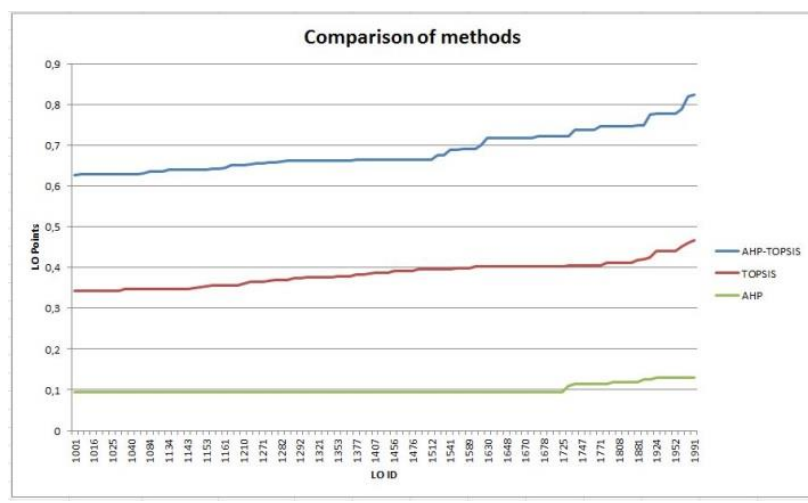

Fig. 3. Comparisons of LO evaluation methods. 


\section{CONCLUSION}

There are a lot of methods for LO evaluation and selection process. Each method has its advantages and disadvantages. In this study, we used AHP-TOPSIS method to prevent difficulties and wastage of time in the e-content producing process. The AHP-TOPSIS combined method, developed in this paper, is more reliable. Drawbacks of the AHP method are eliminated by the help of TOPSIS. Obtained results demonstrate the importance of the method. The Zonesa system is used for evaluation and searching of LOs for similar short range LOs in real case study. Different MCDM methods can be used for presented issue in the future.

\section{ACKNOWLEDGMENT}

The authors thank the Scientific and Technological Research Council of Turkey (TUBITAK) that supported this project financially with project number EEEAG $115 \mathrm{E} 600$.

\section{REFERENCES}

[1] M. Bhaskar, M. M. Das, T. Chithralekha, and S. Sivasatya, "Genetic algorithm based adaptive learning scheme generation for context aware E-learning," Int J Comput Sci Eng, vol. 2, no. 4, pp. 1271-1279, 2010.

[2] J. Vargo, J. C. Nesbit, K. Belfer, and A. Archambault, "Learning object evaluation computer mediated collaboration and inter-rater reliability," Int J Comput Appl, vol. 25, no. 3, pp. 1-8, 2003.

[3] IEEE LTSC Standart. Final Draft Standard for Learning Object Metadata. [Online]. Available: http://grouper.ieee.org/groups/ltsc/wg12/files/LOM_1484_12_1_v1_F inal_Draft.pdf

[4] T. Yigit, A. H. Isik, and M. Ince, "Web-based learning object selection software using analytical hierarchy process," IET Softw, vol. 8, no. 4, pp. 174-183, August 2014.

[5] M. Ince, A. H. Isik, and T. Yigit, "Multi-Criteria approach to learning object selection through fuzzy AHP," Journal of Multiple-Valued Logic \& Soft Computing, vol. 27, no. 1, pp. 1-1, 2016.

[6] D. A. Wiley. Connecting learning objects to instructional design theory: A definition, a metaphor, and a taxonomy. [Online]. Available: http://wesrac.usc.edu/wired/bldg-7_file/wiley.pdf

[7] A. S. Sabitha and D. Mehrotra, "User centric retrieval of learning objects in LMS," in Proc. Third International Conference on Computer and Communication Technology, 2012, pp. 14-19.

[8] A. S. Sabitha and D. Mehrotra, "A push strategy for delivering of learning objects using metadata based association analysis (fp-tree)," in Proc. International Conference on Computer Communication and Informatics, 2013, pp. 1-4.

[9] T. Chellatamilan and R. M. Suresh, "Automatic classification of learning objects through dimensionality reduction and feature subset selections in an e-learning system," in Proc. IEEE International Conference on Technology Enhanced Education, 2012, pp. 1-6

[10] C. S. Yu, "A GP-AHP method for solving group decision-making fuzzy AHP problems," Comput Oper Res, vol. 29, no. 14, pp. 1969-2001, December 2002.
[11] F. A. Mohammed and M. A. E. Hagag, "Integrating AHP and genetic algorithm model adopted for personal selection," Int J Eng Trend Technol, vol. 6, no. 5, pp. 247-256, December 2013.

[12] C.L. Hwang and K. Yoon, Multiple Attribute Decision Making: Methods and Applications, New York: Springer-Verlag, 1981.

[13] M. Tyagi, P. Kumar, and D. Kumar, "A hybrid approach using AHP-TOPSIS for analyzing e-SCM performance," Procedia Engineering, vol. 97, pp. 2195-2203, December 2014

[14] M. Tavana and A. Hatami-Marbini, "A group AHP-TOPSIS framework for human spaceflight mission planning at NASA," Expert Systems with Applications, vol. 38, no. 11, pp. 13588-13603, October 2011.

[15] A. Majumdar, B. Sarkar, and P. K. Majumdar, "Determination of quality value of cotton fibre using hybrid AHP-TOPSIS method of multi-criteria decision-making," Journal of the Textile Institute, vol. 96, no. 5, pp. 303-309, 2005

[16] L. Gao and A. Hailu, "Identifying preferred management options: an integrated agent-based recreational fishing simulation model with an AHP-TOPSIS evaluation method," Ecological modeling, vol. 249, pp 75-83, January 2013

[17] T. L. Saaty, "How to make a decision: the analytic hierarchy process," Eur J Oper Res, vol. 48, no. 1, pp. 9-26, September 1990.

[18] T. L. Saaty, The Analytic Hierarchy Process: Planning, Priority Setting, Resources Allocation, New York: McGraw, 1980.

[19] S. H. Zanakis, A. Solomon, N. Wishart, and S. Dublish, "Multi-attribute decision making: A simulation comparison of select methods," European Journal of Operational Research, vol. 107, no. 3 pp. 507-529, 1998

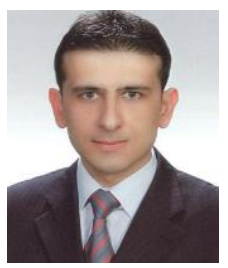

Murat İnce was born in Antalya, 1985. He received the B.S. degree in 2009 from Education Faculty of Middle East Technical University, Turkey. He received M.S. degree in 2012 from Suleyman Demirel University in 2012. He is currently research assistant at the Vocational School of Technical Sciences in Suleyman Demirel University. His research interest includes expert systems, software development and

distance education.

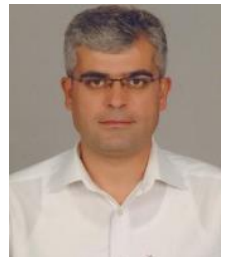

Tuncay Yiğit was born in Isparta, 1974. He received the B.S. degree in 1997 from Technical Education Faculty of Gazi University, Turkey. He received M.S degree in 2000 from Gazi University, Turkey and completed the Ph.D. degree in 2005 at Gazi University. $\mathrm{He}$ is currently professor at the Department of Computer Engineering in Suleyman Demirel University. His research interest includes software technologies, information systems.

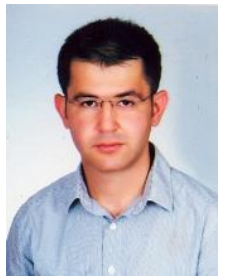

Ali H. Işık was born in Burdur, 1981. He received the B.S. degree in 2002 from electrical and electronics engineering of Gazi University, Turkey. He received M.S. degree in 2005 from Gazi University, Turkey and completed $\mathrm{Ph}$. D. degree in 2012 at Gazi University. $\mathrm{He}$ is currently an assistant professor at the Department of Computer Engineering in Mehmet Akif Ersoy University. His research interest includes computer science, optimization and engineering education. 